\section{Two major genes, linked to HLA and Gm, control susceptibility to Graves' disease}

WE are pleased that Uno et al. ${ }^{1}$ have extended to family material the finding ${ }^{2}$ that variation in 'immunological networks', identified by HLA and Gm allotypes, contributes to Graves' disease susceptibility in a more than additive manner.

However, like Welsh ${ }^{3}$ we regret the uncertainty created by the unspecific but clearly extensive selection of the families analysed by these workers. For example, if as they suggest two dominant alleles are involved, general offspring-parent correspondence between markers and disease, as in the family illustrated ${ }^{1}$ is expected, but not reported. There is evidence that HLA-associated genetic susceptibility to Graves' disease is not dominant but involves the participation of two parental haplotypes ${ }^{4}$, and in a series of 28 affected sib pairs, 68,25 and $7 \%$ shared respectively two, one and no HLA haplotypes, more compatible with recessive or intermediate than dominant action of HLA-associated susceptibility ${ }^{5}$. In one large family having several cases of Graves' disease, HLA patterns were consistent with a dominant association ${ }^{6}$ but $\mathrm{Gm}$ patterns (which have not been reported) are not. Generalization from small numbers of selected families regarding the genetic component in susceptibility to Graves' disease, and possibilities for predictions of risk to relatives $^{3}$, are inappropriate. In Caucasians, the associated HLA and Gm markers are found in 23 and $80 \%$, respectively of the general population, but only $\sim 1 \%$ of the general population and $5 \%$ of sibs of affected persons develop Graves' disease.

We are intrigued with the lack of association between specific allotypes and Graves' disease found by ourselves in Caucasians $^{7}$ and by Nakao et $a l^{8}$ in Japanese individuals, although admittedly different allotypes were involved in the case of the Japanese and were less closely associated with the disease.

Sasazuki's laboratory previously reported $^{9}$ a strong association between Graves' disease and HLA-Dw12 (previously $\mathrm{DHO}$ ), but now report instead an increase in HLA-DR5. This is rather surprising because DR5 seems slightly reduced in Caucasian patients with Graves' disease, and is instead associated with goitrous thyroiditis ${ }^{5}$. Moreover, HLA-DR5 does not exhibit cross-reactivity with HLA-Dw12-positive cells ${ }^{10}$. The authors need to resolve this discrepancy.
In contrast to the mouse, in which idiotypic determinants have been shown to be linked to $C_{H}$ allotypic markers, no such evidence have been provided for humans, whose allotypic markers are located further down the $\mathrm{Fc}$ region ${ }^{11}$. Further work may reveal such an association; meanwhile it is worth considering the possibility that allotype- or isotypespecific networks of immunoregulatory cells may be involved in disease susceptibility $^{5}$. Indeed, immunoglobulin subclass and allotypic restriction of the thyroid stimulating antibody have been demonstrated $^{12,13}$.

\section{NADIR R. FARID JOHN C. BEAR}

Faculty of Medicine,

Memorial University of

Newfoundland

Health Sciences Centre,

St John's, Newfoundland,

Canada A1B 3 V6

1. Uno, H., Sasazuki, T., Tamai, H. \& Matsumoto, H. Nature 292, 768-780 (1981).

2. Farid, N. R., Newton, R. M., Noel, E. P., Barnard, J. M. \& Marshall, W. H. Tissue Antigens 12, 205-211 (1978). Marshall, W. H. Tissue Antigens 12,
Welsh, K. Nature 292,673-674 (1981)

3. Welsh, K. Nature 292, 673-674 (1981).
4. Farid, N. R. et al. Tissue Antigens 15, $492-500$ (1980).

5. Farid, N. R. \& Bear, J. C. in Autoimmune Endocrine Disease (Ed Davies, T. F.) (Wiley, New York, in the press)

6. Farid, N. R., Barnard, J. M., Marshall, W. H., Woolfrey, I \& O'Driscoll, R. F. J. clin. Endocr. Metab. 45, 1165$1172(1977)$

7. Farid, N. R., Newton, R. M., Noel, E. P. \& Marshall, W. H. J. Immunogenet. 4, 429-432 (1977)

8. Nakao, Y. et al. Clin. exp. Immun. 42, 20-26 (1980)

9. Sasazuki, T. et al. New Engl. J. Med. 298, 630-631 (1978)

10. Terasaki, P. I. (ed.) Histocompatibility Testing 1980 (UCLA Tissue Typing Laboratory, Los Angeles, 1980).

Weigert, T., Potter, M. \& Sachs, D. Immunogenetics 1 , 511-523 (1975).

12. Pepper, B., Noel, E. P. \& Farid, N. R. J. Immunogenet. 8 , 89-100 (1981).

13. Zakarija, M. Horm. Res. 13, 1-15 (1980)

SASAZUKI AND UNO REPLY-We reported that two major genes, linked to HLA and Gm, control susceptibility to Graves' disease ${ }^{1}$. Of 30 Japanese families in which more than two first degree relatives were affected, only 15 families had at least two affected siblings, which we could analyse by the sib-pair method ${ }^{2}$. We did not conclude in any way that an HLAlinked disease susceptibility gene for Graves' disease was dominant. Recently we proposed ${ }^{3}$ two genetic models for Graves' disease by analysing the same families using the affected sib-pair method $^{4}$ : (1) an HLA-linked recessive gene (gene frequency $(\mathrm{gf})=0.30$ ) plus a $\mathrm{Gm}$-linked recessive gene $(\mathrm{gf}=0.10)$ with penetrance $>0.60 ;(2)$ an HLA-linked dominant gene $(\mathrm{gf}=0.08)$ plus a $\mathrm{Gm}$ linked recessive gene $(\mathrm{gf}=0.10)$ with penetrance $>0.50$. Due to the small number of affected sib-pairs, we could not distinguish between a dominant and recessive model for an HLA-linked Graves' disease gene. However, we can reject a dominant model if we analyse our data together with those of Farid and Bear ${ }^{5}$ : of 43 affected sib-pairs, 27 shared two, 14 shared one and two shared zero HLA haplotvpes.

There was not significant association between 30 probands with Graves' disease and $\mathrm{Gm} 1,2,21(a, x, z)$ halotype which was reported ${ }^{6}$ to be associated with Graves' disease. Rather in our study this haplotype was decreased in frequency $(0.0860)$ compared with that in the Japanese population (haplotype frequency $=0.1575$ ). Similarly, the present patient group did not show any association with Bw35(w5), which was reported to be associated with Graves' disease in the Japanese patients ${ }^{7}$, where increased frequency of DW12(DHO) was also observed ${ }^{8}$. The present patients under study were selected from multiple case families whereas our previous study and that of Nakao et al. used unselected patients. This may partly explain the discrepancies observed for the statistical association of Graves' disease with the genetic markers, HLA and Gm, between our present study and those of Nakao et $a l^{6}{ }^{6}$, Grumet et $a l^{7}$ and ourselves. This may also explain the observed discrepancy in the frequency of HLA-DR5 between our study and the report of Farid and Bear ${ }^{5}$.

In any event, there are two distinct genes which have a major effect on susceptibility to Graves' disease and which are clearly identified by the genetic markers, HLA and Gm. Clarification of the immunological mechanisms controlled by these major genes awaits elucidation of the environmental factors which are crucial in triggering Graves' disease.

\section{TAKEHIKO SASAZUKI} HISAMITSU UNO

\section{Department of Human Genetics,}

Medical Research Institute,

Tokyo Medical and Dental University, Tokyo 113, Japan

\footnotetext{
1. Uno, H., Sasazuki, T., Tamai, H. \& Matsumoto, H. Nature 292, 768-770 (1981)

2. Penrose, L. S. Ann. Eugen. 6, 133-138 (1935)

3. Sasazuki, T., Uno, H., Yasuda, N., Tamai, H. \& Matsumoto, $\mathrm{H}$. in 6 th int. Congr. of Human Genetics (Liss, New York, in the press)

4. Thomson, G. \& Bodmer, W. F. in Measuring Selection in National Populations (eds Christiansen, T. B. \& Fenchel T. M.) 545-546 (Springer, Berlin, 1977).

5. Farid, N. R. \& Bear, J. C. in Autoimmune Endocrine Disease (Ed. Davies, T. F.) (Wiley, New York, in the Disease (Ed. Davies, T. F.) (Wiley, New York, in
press).

6. Nakao, Y. et al. Clin. exp. Immun. 42, 20-26 (1980)

7. Grumet, F. C., Payne, R. O., Konishi, J., Mori, T. \& Kriss, J. P. Tissue Antigens 6, 347-352 (1975).

8. Sasazuki, T. et al. New Engl. J. Med. 298, 630-631 (1978).
} 